\title{
Análise da produção científica da Fonoaudiologia: experiência no CNPq no período de 2007-2010
}

\author{
Claudia Regina Furquim de Andrade ${ }^{1}$, Léslie Piccolotto Ferreira ${ }^{2}$
}

\section{Prezado Editor,}

Vimos apresentar um estudo que tem como objetivo apresentar, à comunidade científica da Fonoaudiologia, uma análise da produção científica da área, com base exclusiva das ações do CA-MS (Comitê de Assessoramento Multidisciplinar da Saúde: Educação Física, Fisioterapia/Terapia Ocupacional e Fonoaudiologia) do CNPq no período de 2007-2010.

O Conselho Nacional de Desenvolvimento Científico e Tecnológico (CNPq) é uma agência do Ministério da Ciência e Tecnologia (MCT) destinada ao fomento da pesquisa científica e tecnológica e à formação de recursos humanos para a pesquisa no país. Sua história está diretamente ligada ao desenvolvimento científico e tecnológico do Brasil contemporâneo. A estrutura funcional do CNPq compreende uma Diretoria Executiva, responsável pela gestão da instituição, e um Conselho Deliberativo, responsável pela política institucional. Além de participar desses órgãos, a comunidade científica e tecnológica do país participa também em sua gestão e política por meio dos Comitês de Assessoramento e da Comissão de Assessoramento Técnico-Científico.

Para analisar, julgar, selecionar e acompanhar os pedidos de projetos de pesquisa e de formação de recursos humanos, o CNPq conta com o apoio de milhares de pesquisadores que constituem sua Assessoria Científico-Tecnológica. Esses pesquisadores, individualmente ou em grupos, têm atribuições específicas e atuam de acordo com suas especialidades. São mais de 300 pesquisadores, entre titulares e suplentes (estes implementados em 2004), selecionados de acordo com sua área de atuação e conhecimento. Eles são escolhidos periodicamente pelo Conselho Deliberativo (CD), com base em consulta feita à comunidade científico-tecnológica nacional, e integram os Comitês de Assessoramento (CAs), que têm a atribuição, entre outras, de julgar as propostas de apoio à pesquisa e de formação de recursos humanos. O Conselho Deliberativo escolherá os membros titulares e suplentes dos CA(s) entre os pesquisadores bolsistas de Produtividade em Pesquisa de nível I ou entre pesquisadores não bolsistas com o perfil de pesquisadores de nível I. A designação dos membros dos CA(s) será feita por um período de dois ou três anos, sendo vedada a recondução dos titulares

Os Comitês de Assessoramento destinam-se a prestar as-

(1) Professora Titular de Fonoaudiologia da Faculdade de Medicina da Universidade de São Paulo - FMUSP - São Paulo (SP), Brasil; Representante de área no CNPq no triênio 2007-2010.

(2) Professora Titular de Fonoaudiologia da Pontifícia Universidade Católica de São Paulo - PUC-SP - São Paulo (SP), Brasil; Suplente de representação de área no CNPq no triênio 2007-2010. sessoria ao CNPq na formulação de políticas e na avaliação de projetos e programas relativos a sua área de competência, bem como na apreciação das solicitações de bolsas e auxílios. O CD determinará o número de membros de cada CA. Cada CA terá um número de suplentes correspondente à metade do número de titulares, garantida a representação de todas as áreas no caso de $\mathrm{CA}(\mathrm{s})$ que congregam múltiplas áreas.

Compete aos Comitês de Assessoramento:

a) participar do processo de planejamento, avaliação, acompanhamento, e análise das ações relativas às áreas do conhecimento em que atuam;

b) contribuir para a formulação de programas e planos de desenvolvimento científico e tecnológico;

c) recomendar à Diretoria Executiva, ações de fomento em sua área de atuação e

d) analisar as solicitações de bolsas e auxílios, elegendo critérios específicos de julgamento e emitindo parecer fundamentado quanto a seu mérito científico e técnico e a sua adequação orçamentária e recomendando ou não sua concessão, que é atribuição da Diretoria Executiva.

Os comitês de assessoramento estão divididos em três áreas do conhecimento:

- Ciências Humanas e Sociais Aplicadas, com 2 coordenações sub-divididas em 10 comitês de assessoramento, com um total de 57 membros efetivos

- Ciências da Vida, com 6 coordenações sub-divididas em 23 comitês de assessoramento, com um total de 98 membros efetivos

- Engenharias, Ciências Exatas e da Terra com 6 coordenações sub-divididas em 15 comitês de assessoramento, com um total de 83 membros efetivos

As atividades de fomento do $\mathrm{CNPq}$ são organizadas na forma de editais. Os Editais são financiados com recursos próprios do CNPq ou de outros Ministérios e Fundos Setoriais. As regras e normas dos diversos editais são variáveis em função as especificidades de cada um desses editais. De maneira geral esses editais podem ser divididos em duas grandes áreas: bolsas e auxílios.

O CNPq oferece várias modalidades de bolsas aos alunos do ensino médio, graduação, pós-graduação, recém-doutores e pesquisadores já experientes. As bolsas são divididas em duas categorias principais: bolsas individuais no país e no exterior, e bolsas por quota.

$\mathrm{O}$ CNPq oferece várias modalidades de auxílio à pesquisa, tais como: o subsídio a publicações científicas, o apoio à capacitação de pesquisadores por meio de intercâmbios científicos ou da promoção e atendimento a reuniões e congressos científicos. As modalidades de auxílio mais procuradas são: o 
Universal, o Milênio e o Casadinho. Eem parceria com Fundações Estaduais de Apoio à Pesquisa (FAPs) são o Pronex e o Programa Primeiros Projetos.

A Fonoaudiologia, juntamente com a Educação Física; a Enfermagem; a Farmácia; a Fisioterapia; a Medicina; a Odontologia; a Saúde Coletiva e Nutrição e a Terapia Ocupacional, compõe a área de conhecimento das Ciências da Vida. O comitê onde se insere a Fonoaudiologia é chamado de Comitê Assessor Multidisciplinar da Saúde (CA-MS).

Com base nos relatórios oficiais produzidos pelo CA-MS foram elencados todos os julgamentos de editais no triênio 2007-2010. O corpus do estudo foi composto por:

1. Julgamentos das Bolsas de Produtividade em Pesquisa dos anos de 2007, 2008 e 2009

2. Julgamentos dos Editais Universais 2007, 2008, 2009

3. Julgamento das Bolsas Especiais no país e no exterior em todos os cronogramas dos anos de 2008, 2009 e primeira chamada de 2010

4. Julgamento do Edital de Jovem Pesquisador de 2008

5. Edital de Consolidação de Novos Campi e Novas Universidades de 2009

Em relação aos aspectos éticos é importante ressaltar que o estudo aqui apresentado não divulga nenhum resultado que permita a identificação de pesquisadores ou projetos de pesquisa. Os relatórios são de natureza sigilosa, disponibilizados exclusivamente para o CNPq. A natureza do estudo não implica na necessidade de consentimento ou termo de ética, pois apenas descreve e analisa a produção científica de uma área do conhecimento sem juízo de valor ou demérito de qualquer pesquisa/pesquisador.

\section{Julgamentos das Bolsas de Produtividade em Pesquisa dos anos de 2007, 2008 e 2009}

O objetivo da Bolsa de Produtividade em Pesquisa é distinguir o pesquisador valorizando a produção científica no período.

Tabela 1. Relação entre a demanda e o número efetivo de bolsas

\begin{tabular}{lcccc}
\hline Ano & $\begin{array}{c}\text { Demanda } \\
\text { bruta }\end{array}$ & $\begin{array}{c}\text { Bolsas já } \\
\text { existentes }\end{array}$ & Bolsas novas & $\begin{array}{c}\text { Total de } \\
\text { bolsas }\end{array}$ \\
\hline 2007 & 37 & 8 & 5 & 13 \\
2008 & 37 & 4 & 15 & 19 \\
2009 & 60 & 12 & 4 & 16 \\
\hline
\end{tabular}

Os dados se referem aos anos de julgamentos dos editais, em decorrência da mudança de regras quanto ao tempo de duração das bolsas PQ1, introduzidas no julgamento de 2009, no próximo triênio haverá variação nesses dados, ou seja, o número de bolsas a serem renovadas variaará segundo a disponibilidade dos PQ1. Nos anos de 2007 e 2008 os critérios vigentes para o julgamento foram àqueles propostos pelos CA-MS anteriores. No início de 2009 houve um grande esforço dos comitês para ajustes nesses critérios havendo então uma compatibilização entre os critérios específicos das áreas e a proposta de uniformização de regras pelo CNPq. A mudança dos critérios foi favorável às áreas.
Tabela 2. Distribuição de Bolsas PQ1 e PQ2

\begin{tabular}{lccccc}
\hline Ano & PQ2 & PQ1D & PQ1C & PQ1B & PQ1A \\
\hline 2007 & 9 & 0 & 2 & 1 & 1 \\
2008 & 17 & 1 & 0 & 1 & 0 \\
2009 & 14 & 2 & 0 & 0 & 0 \\
\hline
\end{tabular}

No período de 2007 a 2010 houve um crescimento de mais de $100 \%$ no numero de bolsas de produtividade distribuídas pelo CNPq para a área da Fonoaudiologia. No período, a política do CNPq foi a de aumentar o número total de bolsas para as áreas que tivessem demanda qualificada e comprovassem seu mérito de produção científica. Nesse período não houve possibilidade de reclassificação dos pesquisadores $\mathrm{PQ} 2$ para além da cota disponível em PQ1 em cada um dos anos. Para a Fonoaudiologia, no triênio houve o aumento de 1 bolsa PQ1D. Em todos os relatórios enviados nos julgamentos o CA-MS, como um todo, fez proposições de reclassificação com base nas propostas qualificadas de cada demanda.

\section{Julgamentos dos Editais Universais 2007, 2008, 2009}

O objetivo do Edital Universal é apoiar atividades de pesquisa científica, tecnológica e de inovação que visem contribuir significativamente para o desenvolvimento científico e tecnológico do país, em qualquer área do conhecimento e em termos de interesse dos fundos setoriais

Tabela 3. Distribuição de recurso financeiro e atendimento da demanda

\begin{tabular}{|c|c|c|c|c|c|}
\hline Ano & $\begin{array}{l}\text { Total de } \\
\text { recursos }\end{array}$ & $\begin{array}{c}\text { Estados NO/ } \\
\mathrm{NE} / \mathrm{CO}\end{array}$ & $\begin{array}{c}\text { Estados } \\
\text { outros }\end{array}$ & $\begin{array}{c}\text { Demanda } \\
\text { bruta }\end{array}$ & $\begin{array}{c}\text { Demanda } \\
\text { atendida }\end{array}$ \\
\hline 2007 & $203.767,15$ & $61.130,15$ & $142.637,00$ & 42 & 11 \\
\hline 2008 & $243.743,94$ & $73.123,18$ & $170.620,76$ & 48 & 13 \\
\hline 2009 & $210.000,00$ & $70.000,00$ & $140.000,00$ & 46 & 14 \\
\hline
\end{tabular}

O Edital Universal é dividido por Faixas relativas aos montantes solicitados. Dos recursos disponibilizados 30\% cabe, obrigatoriamente, aos projetos oriundos dos estados do Norte, Nordeste e Centro-Oeste. A área da Fonoaudiologia não dispôs de recursos para contemplar os projetos da Faixa C. No triênio a verba que coube à nossa área contemplou entre 26 e $30 \%$ dos projetos enviados. Nesse edital o julgamento se fundamenta na qualidade do projeto associado à produção do pesquisador. Com a política de incentivo à pesquisa para a região NONECO a relação pesquisador/projeto contemplado é de aproximadamente $2 / 1$; para as outras regiões a relação pesquisador/projeto contemplado é de aproximadamente 6/1 (pelas variações das demandas iniciais em cada Edital).

\section{Julgamento das Bolsas Especiais no país e no exterior em todos os cronogramas dos anos de 2008, 2009 e primeira chamada de 2010}

O objetivo das diversas bolsas de fomento é especificado é cada modalidade de Edital.

A demanda da Fonoaudiologia para as bolsas especiais é muito baixa, não atingindo nem 5\% da demanda geral do CA- 
MS como um todo. Das seis chamadas do triênio em quatro delas não houve demanda da Fonoaudiologia ou houve demanda não qualificada, ou seja, o pedido não contemplava as regras do Edital. Nas chamadas onde houve demanda qualificada foram atendidas $25 \%$ das solicitações. Na chamada de ARC (Apoio a Eventos) que é de classificação unificada no CA-MS, no triênio, foram priorizados os dois eventos nacionais, tradicionais da Fonoaudiologia, e contemplados mais três eventos regionais. Importa ressaltar que nesses Editais a classificação é comum, ou seja, não há cota/demanda para cada área do CA-MS. É um processo de julgamento extremamente delicado e político, pois alguns pesquisadores das outras áreas do CAMS tem produção pontuada muito acima da Fonoaudiologia tornando o trabalho da representação da área muito exaustivo. Nossa demanda nesse campo deve ser incentivada, quer nas possibilidades acadêmicas quer nas possibilidades técnicas. Nossos pesquisadores mais produtivos devem direcionar uma atenção especial nesses Editais.

\section{Julgamento do Edital de Jovem Pesquisador de 2008}

Em 2008 foi aberto Edital Específico para Jovem Pesquisador, Faixas A e B. Do total de 215 propostas recebidas pelo CA-MS menos de $10 \%$ eram demanda da Fonoaudiologia, ou seja, o montante financeiro proporcional que foi atribuído para a área atingiu o valor de $\mathrm{R} \$ 68.010,00$ e pode contemplar 2 dos projetos enviados ( $10 \%$ do total da demanda específica que foi de 20 projetos).

\section{Edital de Consolidação de Novos Campi e Novas Univer- sidades de 2009}

Dos 37 projetos apresentados ao CA-MS nenhum era da Fonoaudiologia.

\section{CONSIDERAÇÕES}

Na avaliação das demandas, os Comitês de Assessoramento consolidam uma visão estratégica para as áreas, incentivando as pesquisas que representem novos avanços da ciência, bem como as subáreas ou linhas de pesquisa que não estão bem desenvolvidas no país, mas são relevantes para o desenvolvimento científico de cada uma das áreas.

No triênio 2007-2010, que se finaliza em junho desse ano, o CA-MS apresentou um enorme desenvolvimento para todas as áreas. O CA-MS através de uma ação conjunta e muito trabalhosa obteve o primeiro Edital específico para as áreas da Educação Física, Fisioterapia/Terapia Ocupacional e Fonoaudiologia. Esse Edital foi o de número 58/2009 intitulado "Envelhecimento, Trabalho e Saúde: Promoção da qualidade de vida da população brasileira por meio de atividade física, ocupacional e linguagem" que foi concebido e batalhado no Comitê e pelo Comitê, mas não foi julgado por nós. Esse Edital foi um enorme sucesso com alta demanda de projetos e abriu um importante precedente.

A experiência das autoras, frente à representação da área, nesses três anos comporta algumas sugestões:

1. Nos Editais de classificação geral (como o das bolsas especiais) a Fonoaudiologia apresenta um demanda muito baixa que prejudica a área. Além da pontuação dos pesquisadores da Fonoaudiologia, com restrições, ser mais baixa que as pontuações dos pesquisadores das outras áreas do Comitê nós não criamos demanda, portanto, é quase impossível classificar um projeto;

2. Nessa gestão do CA-MS (e que deixamos como sugestão que seja mantido na próxima) as distribuições de verbas foram proporcionais à demanda o que permitiu o enorme desenvolvimento atingido pela Fonoaudiologia no período;

3. A proporção demanda $x$ atendimento é de: EF 3.7/1; FITO 4.2/1 e FO 3.0/1;

4. A relação demanda bruta $x$ demanda qualificada é de: EF 40\%; FITO 30\% e FO 20\%;

5. A proporção demanda $x$ atendimento para as áreas varia de 10 a 28\% dependendo do tipo de julgamento.

Finalizando, o objetivo desse estudo foi apresentar à comunidade científica da Fonoaudiologia uma análise da produção científica da área, com base exclusiva das ações do CA-MS nos anos de 2007-2010. Entendemos que essa contribuição é de grande valia para fundamentar as propostas enviadas pelos pesquisadores e também como sinalização para superarmos lacunas que a área apresenta no que se refere à competitividade científica.

\section{REFERÊNCIAS}

1. Conselho Nacional de Desenvolvimento Científico e Tecnológico CNPq. [Internet]. [citado 2010 Maio 10]; Disponível em: www.cnpq.br.
2. Comitê Assessor Multidisciplinar da Saúde CA-MS. Relatórios do triênio 2007-2010. 